\title{
Fatores de risco associados a doenças respiratórias em potros Puro Sangue Inglês do nascimento ao sexto mês de vida
}

\author{
Risk factors associated the respiratory diseases in Thoroughbred foals, from birth to six \\ months of life
}

\author{
Leandro do Monte Ribas ${ }^{I^{*}}$ Carina Martins Moraes ${ }^{\mathrm{II}}$ Luciana Araújo Lins $^{\mathrm{I}}$ \\ Eduardo Furtado Flores ${ }^{\mathrm{III}}$ Carlos Eduardo Wayne Nogueira ${ }^{\mathrm{IV}}$
}

RESUMO

Foram avaliados fatores de risco associados à ocorrência de doenças respiratórias em 349 potros Puro Sangue Inglês (PSI) monitorados do nascimento ao sexto mês de vida na região de Bagé, Rio Grande do Sul (RS), Brasil. A partir da avaliação clínica e laboratorial pôde-se registrar a frequência de 9,5\% (33) casos respiratórios, com mortalidade de 0,57\% (2). A ocorrência de casos foi mais elevada nos meses de verão, e potros com idade entre quatro e seis meses foram mais suscetíveis $(P<0,001)$. O desenvolvimento de doenças foi influenciado $(P<0,001)$ pelo sistema de criação e pelas práticas de manejo, os quais aumentaram o potencial de contaminação do ambiente. Na avaliação microbiológica, a maior frequência de isolados foi de Streptococcus equi (57\%), seguido do Rhodococcus equi (17\%), letal em 50\% dos casos. Nenhum caso clínico foi associado ao vírus da influenza equina (EIV) $e$ ao herpesvírus equino (EHV-1-4). Os resultados sugerem que fatores ligados ao manejo, na criação de equinos PSI, parecem contribuir decisivamente para a manifestação da doença respiratória e alertam para a morbidade causada pela adenite equina e a letalidade atribuída à rodococose.

Palavras-chave: potros, doença respiratória, Streptococcus equi, Rhodococcus equi.

\section{ABSTRACT}

Risk factors associated the occurrence of respiratory diseases they were evaluated between 349 Thoroughbred foals, monitored of the birth to the sixth month of life in the region of Bagé-RS-Brazil. From the laboratory and clinical evaluation, the frequency of $9.5 \%$ (33) of respiratory cases with mortality of $0.57 \%$ (2) was recorded. The occurrence of cases was higher in months of summer and foals with age between four and six months were more susceptible $(P<0.001)$. The development of the diseases was influenced $(P<0.001)$ by the breeding system of and management practices that increased the environmental contamination potential. In the evaluation microbiological, , the highest frequency of isolated was of Streptococcus equi (57\%), followed by the Rhodococcus equi (17\%), lethal in $50 \%$ of the cases. No clinic case was associated to the equine influenza virus (EIV) and to the equine herpesvirus (EHV-1-4). The results suggest that connected factors to the management in the breeding of thoroughbred equine are going to contribute decisively for the manifestation of the respiratory disease and alert for the morbidity caused by the equine adenitis and the lethality related to rodococosis.

Key words: foals, respiratory diseases, Streptococcus equi, Rhodococcus equi.

\section{INTRODUÇÃO}

A equinocultura constitui importante segmento do agronegócio brasileiro, traduzido pela movimentação econômica da ordem de $\mathrm{R} \$ 7,3$ bilhões por ano e pela a geração direta e indireta de 3,2 milhões de empregos (ESALQ, 2006). Dessa forma, perdas na criação costumam refletir negativamente no chamado complexo agronegócio cavalo.

Em criatórios do extremo sul do Brasil, o segundo grupo de enfermidades com maior ocorrência em potros jovens ( $<$ seis meses) foram aquelas enfermidades associadas ao trato respiratório, atrás apenas das alterações músculo-esqueléticas (FREY JR,

\footnotetext{
ICurso de Pós-graduação em Ciências Veterinárias, Universidade Federal de Pelotas (UFPel), Pelotas, RS, Brasil. Av. General Osório, 1452/14, 96400-101, Centro, Bagé, RS, Brasil. E-mail: ribas@ufpel.edu.br. *Autor para correspondência.

${ }^{\text {IIC} C u r s o ~ d e ~ P o ́ s-g r a d u a c ̧ a ̃ o ~ e m ~ B i o t e c n o l o g i a ~ A g r i ́ c o l a, ~ U F P e l, ~ P e l o t a s, ~ R S, ~ B r a s i l . ~}$

IIIDepartamento de Veterinária Preventiva, Universidade Federal de Santa Maria (UFSM), Santa Maria, RS, Brasil.

${ }^{\text {IV }}$ Departamento de Clínicas Veterinária, UFPel, Pelotas, RS, Brasil.
} 
2006). Semelhantemente, estudos realizados nos Estados Unidos da América apontaram os quadros de pneumonia como a causa primária de doença e morte em potros jovens PSI com idades inferiores a seis meses de idade (COHEN, 1994). No país norte-americano, a ocorrência de enfermidades respiratórias entre potros PSI foi associada significativamente a características de manejo, dentre elas, a elevada lotação animal (UA ha ${ }^{-1}$ ), o fluxo de equinos transitórios, a ausência da avaliação da transferência de imunidade passiva, a falta de vacinação contra adenite equina e a carência de controle antiparasitário (CHAFFIN et al., 2000).

Em relação à etiologia, consideram-se como principais agentes primários das moléstias respiratórias em potros nessa faixa etária o vírus da influenza equina, o herpesvírus equino (-1-2-4), o Rhodococcus equi, o Streptococcus equi e o Parascharis equorum (SELLON, 2001). O diagnóstico etiológico fundamentado apenas no exame físico se torna difícil e, na maioria dos casos, se faz necessária a utilização de exames auxiliares a partir da coleta de secreções do trato respiratório para pesquisas microbiológicas. Vale salientar a importância do entendimento da epidemiologia e etiopatogenia da doença para que sejam adotadas medidas adequadas de tratamento e controle (MELLOR \& STAFFORD, 2004).

No Brasil, até o momento, são raras as publicações que definem as principais causas de morbidade e mortalidade em função de doenças respiratórias, na criação de equinos (DEPRÁ, 2001; FREY JR., 2006). A falta dessas informações leva veterinários, criadores e proprietários à utilização de dados oriundos de outros locais de criação, como América do Norte e Europa, que possivelmente não retratam a realidade latino-americana. Isso posto, o objetivo deste trabalho foi avaliar fatores de risco associados ao desenvolvimento de doenças respiratórias em potros PSI, do nascimento aos seis meses de idade, em sistemas de criação fechado e aberto, na região do Município de Bagé, Rio Grande do Sul (RS), Brasil.

\section{MATERIAL E MÉTODOS}

Durante o período de julho (2006) a maio (2007), foram acompanhados 349 potros PSI, do nascimento aos seis meses de idade, alojados em quatro propriedades na região do Município de Bagé-RS (31¹9’53”'Sul e 5406’25”Oeste). Essas propriedades foram agrupadas quanto ao sistema de criação e número de potros nascidos. As propriedades A $(n=121)$ e C $(n=60)$, com criação fechada, particular, sem hospedagem para cavalos de terceiros, sem fluxo de equinos transitórios. As propriedades B (n=105) e D ( $n=63)$, com criação aberta, prestadoras de serviço, com hospedagem e criação de cavalos para terceiros, com fluxo de equinos transitórios.

O desmame foi realizado aos seis meses de idade nas quatro propriedades. Nas propriedades "B" e “C”, a vacina (Labac/UFSM, Santa Maria, RS) contra adenite equina foi realizada nos potros aos dois meses e no desmame. Todos os potros monitorados receberam antiparasitários (ivermectina + febendazole + piperazina) aos dois meses e no desmame.

Os potros foram monitorados diariamente, durante 180 dias, com atenção direcionada para as alterações de comportamento e atitude, avaliadas secundariamente a partir do exame físico geral e dos meios auxiliares de diagnóstico. Foram incluídos no grupo de doentes os potros com sinais clínicos de doença respiratória: secreções nasais, adenite em linfonodos regionais da cabeça, tosse, alterações no movimento e frequência respiratória, ruídos traqueais e pulmonares anormais.

Dos potros considerados doentes, foram coletadas amostras de sangue para a obtenção de soro, nos momentos referentes à fase aguda, 24h após o aparecimento dos sinais clínicos, e no período convalescente da doença, 21 dias após a supressão dos sinais clínicos. Amostras de secreções do trato respiratório anterior foram coletadas da cavidade nasofaríngea com auxílio de swab estéril. Do trato respiratório posterior, foram coletadas amostras por lavado nasotraqueal (CRISMAN et al., 1992). O monitoramento de infecções parasitárias foi realizado a partir da contagem de ovos por grama de fezes (OPG) na fase aguda da doença respiratória. As fezes foram coletadas diretamente da ampola retal para a realização do OPG por meio da técnica de McMaster (CRAIG et al., 2007), com sensibilidade para um mínimo de 50 OPG.

As secreções do trato respiratório foram avaliadas por métodos rotineiros de culturas em ágar sangue e Mac Conkey para a presença de bactérias. A diferenciação de cepas de Streptococcus spp. foi realizada a partir do kit comercial de fermentação de açúcares em microplaca, API 20 STREP(BioMérieux Brasil S/A, São Paulo, SP), constituído por testes bioquímicos com alto poder discriminatório (SILVA \& VARGAS, 2006). A caracterização de cepas patogênicas de Rhodococcus equi foi realizada com base no sequenciamento genético da proteína VapA a partir da amplificação pela reação em cadeia da polimerase/PCR (HASHIKURA et al., 2000).

As evidências de infecções pelo herpesvírus equino e influenza equina foram avaliadas respectivamente pelos testes de soroneutralização viral 
e inibição da hemaglutinação a partir da soroconversão em amostras pareadas com intervalos de três semanas a partir do desaparecimento dos sinais clínicos da doença. A tentativa de isolamento viral foi realizada em monocamadas de cultivos celulares suscetíveis (DIEL et al., 2006).

Na ocorrência de óbito, foi realizada necrópsia com especial atenção para a avaliação macroscópica dos órgãos do sistema respiratório. $\mathrm{O}$ exame histopatológico foi realizado a partir de fragmentos pulmonares e traqueais fixados em solução formalina $10 \%$ e corados com hematoxilina-eosina.

Semelhantemente ao proposto por CHAFFIN et al. (2000), os fatores de risco avaliados incluíram o total de equinos na propriedade ( $n$ de equinos), o total de potros jovens na propriedade ( $n$ de potros < seis meses), a lotação de equinos (UA ha ${ }^{-1}$ ), o fluxo de equinos transitórios (sim versus não), o transporte do potro em caminhão (sim versus não), a área do tronco de exame ginecológico (único versus variado) e a vacinação do rebanho contra adenite equina (sim versus não).

A frequência de doenças respiratórias foi avaliada pelo teste qui-quadrado em função das variáveis: sistema de criação, idade do potro e fatores de risco. A associação entre elas foi comparada pelo teste de regressão logística condicional. Todas as análises foram conduzidas com o uso do programa Statistix $^{\circledR}$ (2003).

\section{RESULTADOS E DISCUSSÃO}

Entre os 349 potros monitorados, foi registrada a frequência de 9,5\% (33) de doenças respiratórias, com mortalidade de 0,57\% (02) (Tabela $1)$. O resultado foi inferior ao observado por HOFFMAN et al. (1993), no Texas (80\% morbidade e
12\% mortalidade), e por COHEN (1994), em Ontário (70\% e 10\% respectivamente). Os autores supracitados monitoraram rebanhos de equinos em manejo intensivo, o que possivelmente colaborou para a maior casuística. Nessa comparação com propriedades endêmicas, os resultados deste estudo demonstraram que, no período avaliado, as doenças do trato respiratório não ofereceram um risco considerável para a criação; entretanto, foi registrada uma pequena porcentagem de óbitos que reforçam a situação em que mortes podem ocorrer em função de moléstias respiratórias (SELLON, 2001).

A maior ocorrência de casos clínicos foi observada nas propriedades " $B$ " $\mathrm{e}$ " $D$ " e foi associada significativamente $(\mathrm{P}<0,001)$ às características observadas no sistema de criação aberto, tais como lotação de equinos (1UA ha-1), fluxo transitório de equinos, transporte dos potros em caminhão fechado e a mesma área do tronco para exame ginecológico. O resultado é semelhante ao descrito por CHAFFIN et al. (2000) e reforça a opinião de diferentes autores (COHEN et al., 2001; CHAFFIN et al., 2003) a respeito de quais enfermidades do trato respiratório são exacerbadas a partir da potencial contaminação ambiental por secreções nasais e fezes de equinos portadores assintomáticos ou com doença clínica.

Pôde-se observar que potros com idades entre quatro e seis meses foram mais suscetíveis $(\mathrm{P}<0,001)$ à ocorrência de enfermidades (Tabela 2). Em relação ao período do ano, a maior concentração (64\% - 21) de casos clínicos respiratórios foi registrada nos meses de verão (médias da temperatura e umidade do ar, respectivamente, $28^{\circ} \mathrm{C}$ e $72 \%$ ). A frequência nesse período coincidiu com o término da temporada reprodutiva e consequentemente com a maior densidade populacional, que, por si só, já favoreceria o desenvolvimento de enfermidades (COHEN et al.,

Tabela 1 - Distribuição da morbidade e da mortalidade associadas a doenças respiratórias entre 349 potros Puro Sangue Inglês monitorados do nascimento aos 180 dias de vida (desmame) na região de Bagé-RS-Brasil.

\begin{tabular}{|c|c|c|c|c|c|c|c|c|c|c|}
\hline \multirow{3}{*}{ Propriedade / criação } & \multirow{3}{*}{ Potros monitorados } & \multirow{2}{*}{\multicolumn{2}{|c|}{----Doentes---- }} & \multirow{2}{*}{$\dagger$} & \multicolumn{6}{|c|}{---------------'Via respiratória afetada--------------- } \\
\hline & & & & & \multicolumn{2}{|c|}{----Anterior---- } & \multicolumn{2}{|c|}{----Posterior---- } & \multicolumn{2}{|c|}{-----Mista----- } \\
\hline & & $\mathrm{n}$ & $\%$ & $\mathrm{n}$ & $\mathrm{n}$ & $\%$ & $\mathrm{~N}$ & $\%$ & $\mathrm{n}$ & $\%$ \\
\hline A / fechada & 121 & $05^{\mathrm{a}}$ & 04 & - & 03 & 60 & 01 & 20 & 01 & 20 \\
\hline B / aberta & 105 & $13^{\mathrm{b}}$ & 12 & 02 & 08 & 62 & 03 & 23 & 02 & 15 \\
\hline C / fechada & 60 & $05^{\mathrm{a}}$ & 08 & - & 04 & 80 & 01 & 20 & - & - \\
\hline D / aberta & 63 & $10^{\mathrm{b}}$ & 16 & - & 05 & 56 & 04 & 33 & 01 & 11 \\
\hline Total & 349 & 33 & 9,5 & 02 & 20 & 61 & 09 & 27 & 04 & 12 \\
\hline
\end{tabular}

$\dagger$ potros que morreram.

Letras distintas em sobrescrito diferem significativamente $(\mathrm{P}<0,001)$. 
Tabela 2 - Distribuição da frequência de doenças respiratórias em relação à idade dos 349 potros Puro Sangue Inglês monitorados do nascimento aos 180 dias de vida (desmame), na região de Bagé-RS-Brasil.

\begin{tabular}{lcccc}
\hline & & & & \\
Idades (dias) & $\mathrm{n}$ & $\% *$ & $\% * *$ & \\
& & $\%$ & $\mathrm{n}$ \\
\hline 0 a 59 & $06^{\mathrm{a}}$ & 1,7 & 18 & 02 \\
60 a 119 & $07^{\mathrm{a}}$ & 2,0 & 21 & - \\
120 a 180 & $20^{\mathrm{b}}$ & 5,8 & 61 & - \\
\hline
\end{tabular}

*Em relação ao total do rebanho monitorado

** Em relação aos doentes

$\dagger$ potros que morreram.

Letras distintas em sobrescrito diferem significativamente $(\mathrm{P}<0,001)$

2005). Além disso, SWEENEY et al. (2005) mencionam que infecções respiratórias, como a adenite equina, costumam ocorrer a partir dos quatro meses de idade, combinando com o término ou declínio da imunidade materna. Para DEPRÁ et al. (2001), a condição de calor e seca, característica da região de Bagé nos meses de verão, aumenta a poeira no ar, favorecendo a multiplicação do $\boldsymbol{R}$. equi e consequentemente o risco de infecções em potros suscetíveis.

A redução nos casos clínicos a partir da metade do mês de fevereiro de 2007 pode ser atribuída ao aumento no número de desmames (SELLON, 2001), prática que contribuiu consideravelmente para a redução da população de potros nos criatórios “A” e "C", pois estes foram recriados distantes do restante do rebanho. Esse manejo parece ter colaborado para a menor ocorrência de doenças nesses dois criatórios, uma vez que, nas propriedades " $B$ ” e “ $D$ ”, os potros desmamados foram mantidos em contato com os lactantes, aumentando, dessa forma, o contato entre categorias de animais e consequentemente o risco de desenvolvimento da doença respiratória.

Para a coleta de amostras, foram descartados 10 potros, tendo em vista que sete já haviam sido medicados com antibióticos e três haviam recebido restrições dos proprietários. Portanto, a discussão dos resultados da microbiologia será realizada a partir das amostras de 23 potros doentes.

Os valores do OPG mínimos e máximos verificados foram 100 e 250 respectivamente, com média aritmética de 156,95 ( $\pm 39,01)$, demonstrando que não ocorreram infecções parasitárias representativas, fato que colaborou para a baixa ocorrência de doenças, pois a terapia anti-helmíntica ineficaz em um rebanho densamente povoado pode predispor a infecção por Parascaris equorum e, consequentemente, lesões pulmonares causadas após a migração das larvas do ascarídeo com infecção bacteriana secundária (SELLON, 2001; CRAIG et al., 2007).

A ausência do EHV e EIV, demonstrada nos cultivos celulares e nas provas sorológicas pareadas, possivelmente colaborou com a baixa frequência de enfermidades. Embora neste trabalho as viroses respiratórias não tenham sido associadas à ocorrência de doenças, estudos sorológicos alertam para a presença de agentes virais nos rebanhos equinos, no Estado do Rio Grande do Sul (DIEL et al., 2006). Dos 65 municípios avaliados pelos autores, na sua grande maioria pertencentes à região Norte do Estado, em 84,6\% (55) destes, pelo menos um equino apresentou altos títulos de anticorpos para o vírus da influenza equina, 15 para arterite viral equina e 12 para herpes vírus equino. Outrossim, foram observados elevados graus de infecções virais nos potros jovens de diferentes centros de criação com problemas de doença respiratória (WANG et al., 2007), demonstrando a importância da inclusão desse grupo de moléstias nos diagnósticos diferenciais.

Em 91\% (21) das amostras de secreções do trato respiratório (14 do trato anterior e sete do posterior), foram identificados agentes infecciosos, restando apenas duas amostras do trato anterior com resultados negativos. Não ocorreram infecções mistas entre as amostras avaliadas. A porcentagem de isolados obtidos no presente trabalho foi satisfatória, pois segundo HOFFMAN et al. (1993), em culturas de secreções do trato respiratório de cavalos adultos e potros, valores acima de $90 \%$ são positivos.

A maior frequência de isolados foi de Streptococcus equi (57\% - 13), resultado que justifica a maior porcentagem (61\%) de alterações clínicas no trato respiratório anterior, como secreção nasal mucopurulenta, tosse, disfagia, e abscessos submandibulares, ambas as manifestações clínicas comuns nas infecções por Streptococcus spp. (SILVA \& VARGAS, 2006). A infecção foi observada em maior porcentagem, em potros próximos ao desmame (quatroseis meses). De acordo com TIMONEY (2004), a doença costuma manifestar-se em potros mais velhos ( $>9$ meses), mas pode ocorrer a partir dos quatro meses de vida, coincidindo com o término ou declínio da imunidade materna.

Dez casos de adenite equina foram registrados nos meses de verão, caracterizados por temperaturas elevadas com baixa umidade no ar, características da região de Bagé. O restante, três casos, foram registrados nos meses de inverno, corroborando a capacidade que o agente tem de sobreviver e se disseminar em todas as épocas do ano (SILVA \& 
VARGAS, 2006). Não foi observada diferença significativa entre vacinados e não vacinados contra a infecção, possivelmente pela ineficácia das vacinas comerciais na formação de anticorpos séricos e imunidade local na nasofaringe, como proposto por FLOCK et al. (2004) e SILVA \& VARGAS (2006).

Os demais agentes bacterianos isolados foram o Rhodococcus equi (17\% - 4), Streptococcus zooepidemicus (13\% - 3) e Staphylococcus spp. (4\% 1). O percentual de isolados de $\boldsymbol{R}$. equi foi inferior aos mencionados por BECÚ et al. (2000), na Argentina, e DEPRÁ et al. (2001), no Brasil. Entretanto, alertam para a elevada letalidade da infecção, semelhante ao proposto por RIBEIRO et al. (2005). A doença foi observada em potros com idade entre um e dois meses. Sabe-se que potros com idade entre um e três meses são considerados suscetíveis ao desenvolvimento de pneumonias, em consequência da infecção por $\boldsymbol{R}$. equi, especialmente aqueles com falhas na transferência de imunidade passiva (PEIRÓ et al., 2002). Os dois óbitos registrados ocorreram em função da infecção por $\boldsymbol{R}$. equi $\mathrm{e}$ foram atribuídos à pneumonia piogranulomatosa focal e pneumonia intersticial aguda grave, patogenia descrita como a principal causa de morte associada à rodococose (GUIGUÈRE, 2001).

Os isolados de $\boldsymbol{S}$. zooepidemiccus demonstraram a importância do diagnóstico diferencial para a instituição do tratamento e o controle específicos da infecção. Conforme SILVA \& VARGAS (2006), esse agente comumente é confundido com infecções por $\boldsymbol{S}$. equi e $\boldsymbol{R}$. equi, podendo causar desde pneumonias a outras enfermidades leves do trato respiratório anterior. Além dos Streptococcus spp., SELLON (2001) descreve diversas outras bactérias aeróbias menos nocivas e envolvidas no desenvolvimento de doenças respiratórias em potros, como os Staphylococcus spp. Esse grupo de agentes foi o único isolado na amostra de um potro com discreta secreção nasal serosa; porém, a identificação pode estar mais relacionada à contaminação da amostra (LÉGUILLETTE et al., 2002), o que não descarta sua relação nos diagnósticos diferenciais.

\section{CONCLUSÕES}

Em resumo, a ocorrência de enfermidades respiratórias não ofereceu um risco considerável aos potros nas propriedades monitoradas, principalmente quando comparada à realidade de criatórios com doença endêmica. Porém, os resultados obtidos no presente estudo indicam que fatores ligados ao manejo na criação de cavalos PSI parecem contribuir decisivamente para o desenvolvimento da enfermidade respiratória e ainda atentam para a morbidade causada pela adenite equina e a letalidade associada à rodococose.

\section{REFERÊNCIAS}

BECÚ, T. et al. Prevalence of virulence plasmids in soil isolates of Rhodococcus equi from 5 horse-breeding farms in Argentina. Journal of Equine Science, v.11, p.23-27, 2000. Disponível em: http://dx.doi.org/10.1294/jes.11.23. Acesso em: 11 mai. 2008. doi: $10.1294 /$ jes.11.23.

CHAFFIN, M.K. et al. Farm management practices associated with Rhodococcus equi pneumonia of foals. In: ANNU MEET OF AAEP, 46., 2000, San Antonio, Texas. Proceedings... San Antonio: American Association Of Equine Practitioners, 2000. V.46. 465p. p.306-307.

CHAFFIN, M.K. et al. Foal-related risk factors associated with development of Rhodococcus equi pneumonia on farms with endemic infection. Journal American Veterinary Medical Association, v.223, n.12, p.1791-1799, 2003. Disponível em: http://dx.doi.org/10.2460/javma.2003.223.1791. Acesso em: 24 out. 2007. doi: 10.2460/javma.2003.223.1791.

COHEN, N.D. Causes of and farm management factors associated with disease and death in foals. Journal American Veterinary Medical Association, v.204, n.10, p.1644-1651, 1994.

COHEN, N.D. et al. Evidence that foals with Rhodococcus equi pneumonia become infected early in life. In: ANNU MEET OF AAEP, 47., 2001, San Diego, Califórnia. Proceedings... San Diego: American Association Of Equine Practitioners, 2001. V.47. 462p. p.403-406.

COHEN, N.D. et al. Farm characteristics and management practices associated with development of Rhodococcus equi pneumonia in foals. Journal American Veterinary Medical Association, v.226, n.3, p.404-413, 2005. Disponível em: http://dx.doi.org/10.2460/javma.2005.226.404. Acesso em: 03 jan. 2008. doi: 10.2460/javma.2005.226.404.

CRAIG et al. Evidence of ivermectin resistance by Parascaris equorum on a Texas horse farm. Journal of Equine Veterinary Science, v.27, n.2, p.67-71, 2007. Disponível em: http://dx.doi.org/10.1016/j.jevs.2006.12.002. Acesso em 03 jan. 2008. doi: 10.1016/j.jevs.2006.12.002.

CRISMAN, M.V. et al. Effects of transport on constituents of bronchoalveolar lavage fluid from horses. Cornell Veterinary, v.82, p.233-246, 1992.

DEPRÁ N.M. et al. Monitoramento da infecção por Rhodococcus equi em potros puro sangue de corrida. Arquivo Faculdade Veterinária - UFRGS, v.29, n.1, p.25-35, 2001.

DIEL, D.G. et al. Prevalência de anticorpos contra os vírus da influenza, da arterite viral e herpesvírus em eqüinos do Estado do Rio Grande do Sul, Brasil. Ciência Rural, v.36, n.5, p.14671473, 2006. Disponível em: http://dx.doi.org/10.1590/S0103847820066000500019\&lng=pt\&nrm=isso. Acesso em: 14 abr. 2008. doi: 10.1590/S0103-84782006000500019. 
ESALQ. Estudo do complexo do agronegócio cavalo. Brasília: Centro de Estudos Avançados em Economia Aplicada da Escola Superior de Agricultura Luiz de Queiroz, 2006. 68p. (Coletânea de Estudos Gleba, 40).

FLOCK, M. et al. Recombinant Streptococcus equi proteins protect mice in challenge experiments and induce immune response in horses. Infection and Immunity.v.72, n.6, p.3228-3236, 2004. Disponível em: http://dx.doi.org/10.1128/ IAI.72.6.3228-3236.2004. Acesso em: 13 jun. 2007. doi: 10.1128/IAI.72.6.3228-3236.2004.

FREY JR., F. Índices epidemiológicos em potros Puro Sangue de Inglês, do nascimento ao sexto mês de vida, na região de Bagé-RS. 2006. 46f. Dissertação (Mestrado em Medicina Veterinária) - Curso de Pós-graduação em Veterinária, Universidade Federal de Pelotas.

GUIGUÈRE, S. Rhodococcus equi pneumonia. In: ANNU MEET OF AAEP, 47., 2001, San Diego, Califórnia. Proceedings... San Diego : American Association of Equine Practitioners, 2001. V.47. 462p. p.465-467.

HASHIKURA, S. et al. Evaluation of nasotracheal aspiration as a diagnostic tool for Rhodococcus equi pneumonia in foals. Equine Veterinary Journal, v.32, n.6, p.560-564, 2000.

HOFFMAN, A.M. et al. Clinical and endoscopic study to estimate the incidence of distal respiratory tract infection in Thoroughbred foals on Ontario breeding farms. American Journal Veterinary Research, v.54, p.1602-1607, 1993.

LÉGUILlETTE, R. et al. Foal pneumonia. In: P. Lekeux (Ed.). Equine respiratory diseases. Publisher: International Veterinary Information Service, 2002. Acessado em 15 maio 2007. Online. Disponível em: http://www.ivis.org/ special_books/Lekeux/lavoie/IVIS.pdf.

MELLOR, D.J.; STAFFORD, K.J. Animal welfare implications of neonatal mortality and morbidity in farm animals. Veterinary Journal, v.168, n.2, p.118-133, 2004. Disponível em: http://dx.doi.org/10.1016/j.tvjl.2003.08.004. Acesso em: 18 mai. 2007. doi: 10.1016/j.tvjl.2003.08.004.

PEIRÓ, R.J. et al. Pneumonia em potros causada pelo Rhodococcus equi. Revista de Educação Continuada, v.5, n.1, p.73-86, 2002.

RIBEIRO, M.G. et al. Molecular epidemiology of virulent Rhodococcus equi from foals in Brazil: virulence plasmids of 85-kb type I, 87-kb type I, and a new variant, 87-kb type III. Comparative Immunology, Microbiology and Infection Diseases, v.28, n.1, p.53-61, 2005. Disponível em: http:// dx.doi.org/10.1016/j.cimid.2004.07.001. Acesso em: 07 abr. 2007. doi: 10.1016/j.cimid.2004.07.001

SELLON, D.C. Investigating outbreaks of respiratory disease in older foals. In: ANNU MEET OF AAEP, 47., 2001, San Diego, Califórnia. Proceedings... San Diego: American Association Of Equine Practitioners, 2001. V.47. 462p. p.447455 .

SILVA, M.S.; VARGAS, A.C. Adenite eqüina-Aspectos clínicos, agente etiológico e métodos de diagnóstico. Arquivos do Instituto Biológico, v.73, n.4, p.493-498, 2006.

SWEENEY, C. et al. Review of Streptococcus equi infections in horses: guidelines for treatment, control, and prevention of strangles. In: ANNU MEET OF AAEP, 51., 2005, Seattle, Washington. Proceedings... Seattle : American Association Of Equine Practitioners, 2005. V.51. 466p.

TIMONEY, J.F. The pathogenic equine streptococci. Veterinary Research, v.35, p.397-409, 2004. Disponível em: http://dx.doi.org/10.1051/vetres:2004025. Acesso em: 10 nov. 2007. doi: 10.1051/vetres:2004025.

WANG, L. et al. Detection of respiratory herpesviruses in foals and adult horses determined by nested multiplex PCR. Veterinary Microbiology, v.121, n.1-2, p.1828, 2007. Disponível em: http://dx.doi.org/10.1016/ j.vetmic.2006.11.009. Acesso em: 12 mai. 2008. doi: $10.1016 /$ j.vetmic.2006.11.009. 